\title{
Comment on "Air Embolism"
}

\author{
Gernot $\operatorname{Rott}^{1}$
}

Received: 20 August 2018/ Accepted: 23 August 2018/Published online: 30 August 2018

(C) Springer Science+Business Media, LLC, part of Springer Nature and the Cardiovascular and Interventional Radiological Society of Europe (CIRSE) 2018

\section{Dear Editor,}

I would like to comment on the publication "TransCatheter Aspiration of Systemic Air Embolism Causing Cardiac Compromise During CT-Guided Lung Biopsy, a Potentially Lifesaving Maneuver" by El Homsi et al [1].

The following items have to be mentioned:

1. The case described is a good example for the fact that the technique of using a "water-seal" (or "saline-drop", or similarly "finger or cap on the needle") to prevent air embolism during coaxial lung biopsy does not work. The statement "Air was noticed to come out of the coaxial needle" clearly shows that the coaxial needle had been opened to the atmosphere-if air can get out, it also can get in. We are convinced that the only way to eliminate the risk of opening the guiding cannula to the atmosphere in coaxial-biopsy of lung-lesions is the use of a hemostatic valve. The so-called "hemostatic-valvecoaxial-biopsy-technique" has been described in detail in our publication from 2014 [2].

2. There is obviously a fundamental misunderstanding regarding the well-founded recommendation of Freund et al. to "locate the lesion below the level of the left atrium" to prevent air embolism [3]. What is relevant in this respect alone is the position of the lesion in relation to the left atrium during biopsy (!) and not in supine position during the diagnostic computed tomography scan. The figure of the biopsy clearly shows the lesion high above the level of the left atrium, as the

Gernot Rott

info@myom-therapie.de

1 Radiological Department, Bethesda-Hospital Duisburg, Duisburg, Germany patient position is "contralateral-dependent" instead of the recommended "ipsilateral-dependent" $[2,4,5]$.

Systemic air embolism in the described case presumably could have been prevented if the current principles of percutaneous lung biopsy would have been followed.

Nevertheless, I congratulate the authors for their lifesaving intervention.

\section{Compliance with Ethical Standards}

Conflict of interest The author declares that he has no conflict of interest.

\section{References}

1. El Homsi M, Haydar A, Dughayli J, Al-Kutoubi A. Trans-catheter aspiration of systemic air embolism causing cardiac compromise during CT-guided lung biopsy, a potentially lifesaving maneuver. Cardiovasc Interv Radiol. 2018. https://doi.org/10.1007/s00270018-2055-4.

2. Rott G, Boecker F. Influenceable and avoidable risk factors for systemic air embolism due to percutaneous CT-guided lung biopsy: patient positioning and coaxial biopsy technique-case report, systematic literature review, and a technical note. Radiol Res Pract. 2014;2014:349062. https://doi.org/10.1155/2014/ 349062.

3. Freund MC, Petersen J, Goder KC, Bunse T, Wiedermann F, Glodny B. Systemic air embolism during percutaneous core needle biopsy of the lung: frequency and risk factors. BMC Pulm Med. 2012;6(12):2 .

4. Rehwald R, Loizides A, Wiedermann FJ, Grams AE, Djurdjevic T, Glodny B. Systemic air embolism causing acute stroke and myocardial infarction after percutaneous transthoracic lung biopsy—a case report. J Cardiothorac Surg. 2016;11(1):80. https://doi.org/10.1186/s13019-016-0478-z.

5. Rott G. Comment on "CIRSE guidelines on percutaneous needle biopsy (PNB)". Cardiovasc Interv Radiol. 2017;40:1958. https:// doi.org/10.1007/s00270-017-1746-6. 